\title{
PERSPECTIVES ON READING, LANGUAGE ARTS, AND LEARNING DISABILITIES
}

Gaye McNutt

The current special issue of the Learning Disability Quarterly (LDQ) marks the first time a specific academic area has been chosen as a focus. The following three reasons justify the selection of reading (and the broader area of language arts) over other academic areas. First, reading is a common topic of articles in the field of learning disabilities. For example, the first two volumes of the LDQ devoted $40 \%$ of the articles to reading and/or language arts. Many other articles alluded to reading (e.g., by listing reading tests as a part of the battery used to identify LD students). Second, research has indicated that reading is a major focus in LD programs. For example, in studying Child Service Demonstration Centers for LD students, Kirk and Elkins (1975) concluded that $80 \%$ of the instructional focus of these centers was on remedial reading. Reinforcing this finding, Kaluger and Kolson (1978) stated that " 85 to $90 \%$ of all LD children have reading problems" (p. 4). Third, there appears to be a general consensus among LD professionals that reading is important to the field of learning disabilities. The following quotations are but a few examples:

- "As the field of learning disabilities has expanded, reading problems have become a major focus of its practitioners" (Bryan \& Bryan, 1978, p. 210).

- "With minor exceptions the terms learning disabled and reading disabled apply to the same children and are so used here" (Haring \& Bateman, 1977, p. 126).

- "Many disabled learners, though not all, have difficulty learning to read" (Kirk, Kliebhan, \& Lerner, 1978, pp. 7-8).

- "Most LD children cannot read well" (Mercer, 1979, p. 198).

- "A large number of children with learning disabilities have specific problems in reading" (Wallace \& McLoughlin, 1979, p. 37).

\section{CURRENT PERSPECTIVES ON THE RELATIONSHIP BETWEEN LANGUAGE ARTS AND LEARNING DISABILITIES}

Because of the emphasis on reading within the field of learning disabilities, it seems natural that the first LDQ topical issue to feature a

GAYE MCNUTT, Ph.D., is Area Coordinator of Special Education, University of Oklahoma. 
particular academic area should focus on reading. This special issue was broadened to include the other language arts in addition to reading primarily because of input from professionals across the nation. Before discussing the input received from these LD professionals, some current perspectives will be presented on the relationship of reading and the broader domain of language arts to the field of learning disabilities.

This section will include a discussion of 1) the belief that reading should be viewed within the context of a general model of language, and 2) holistic reading or language arts.

\section{Reading Within a Language Model}

In a simplified two-dimensional model of language, one dimension usually represents the expressive and receptive aspects of language, while the second represents its written and spoken aspects. Four basic components emerge from such a model: (a) oral expressive language, or speaking; (b) oral receptive language, or listening; (c) written expressive language, or writing; and (d) written receptive language, or reading. Each of these components may include various subdivisions; for example, creative expression, style, spelling, and penmanship might be subsumed under writing. These language components and their subdivisions form the basis of the language arts program in most schools, although different programs will emphasize various components depending on the age of the students, the philosophy of the school system, and the individual teacher.

Two lines of thought seem to predominate many language arts programs. First, many professionals assume that an adequate oral language base must be established before reading instruction can begin. Second, children must possess basic reading skills before they can become competent in writing.

Recent research suggests that at least one of the above assumptions is not as accurate as previously might have been believed. In a review of the literature, Hammill and McNutt (in press) located 322 studies which correlated reading with numerous other variables. Three findings from this review relate to the present discussion: (a) a very strong relationship exists between written expressive language (i.e., spelling, writing conventions, and written grammar) and reading; (b) a weak relationship exists between oral receptive language and reading when school-aged students are studied; and (c) practically no relationship exists between oral expressive language and reading when school-aged students are studied.

Although a high correlation does not warrant the conclusion that a causal relationship exists between two variables, a low or negligible correlation does indicate the absence of any causal relationship. Consequently, the validity of the assumption that adequate oral language is a prerequisite to learning to read is seriously in question. While our review of the research could lend credence to the assumption that reading must precede writing, it may also be interpreted to mean that reading and writing develop simultaneously. Further research obviously is needed.

No conclusive evidence supports the theory that the components of language develop simultaneously. Still, this idea is gaining popularity in many professional fields along with the belief that these abilities should be presented in an integrated or holistic language arts program. Some ideas related to a holistic approach to reading or language arts are presented below.

\section{Holistic Reading or Language Arts}

Holistic is a professionally amorphous term which is used in many different ways. Conversely, many other terms are used that are similar to holistic in meaning. Rather than attempting to identify all areas of study and all individuals whose ideas have contributed to the holistic language arts approach, this overview will concentrate on language arts based on the contributions of Frank Smith and Kenneth and Yetta Goodman. This decision is arbitrary and is not meant to deny the important contributions of individuals such as Blumenthal (1977), Brown (1970), Bruner (1973), Chomsky (1965), Halliday (1951), Huey (1908/1968), Miller (1951), Piaget (1971), and Vygotsky (1936/1962), among others. ${ }^{1}$

Frank Smith, a cognitive psychologist, draws heavily from two theoretical orientations: information-processing theory and psy- 
cholinguistics. Kenneth and Yetta Goodman have focused on linguistics and psycholinguistics (i.e., an interdisciplinary field of study where psychology and linguistics intersect). While much of their work has been devoted to reading, their ideas apply to the broader areas of language arts in general. Thus, when the term reading is used, readers may assume that the information is equally applicable to the other language components.

Throughout their writings K. Goodman and Smith (1971) have emphasized that educators need to know the process or nature of reading and learning to read before they begin to work with students. In fact, “. . . a deeper understanding of what is involved in reading, and in learning to read, is far more important ... than any expectation of better and more efficacious instructional materials" (Smith, 1973, vi).

In discussing the intricacies and capabilities of the human mind, Smith $(1975,1978,1979)$ illustrates that teachers can only facilitate learning and that this can be accomplished best through familiarity with the learning processes. ${ }^{2}$ Students are not passive learners into which we can "pour" needed knowledge. Rather, each student is unique with an individual background and resources of his/her own. Consequently, the learning process must take these unique aspects into account. Smith (1979) further emphasizes that

The real skills of reading that have made readers out of you and me, are not skills that are formally taught at school or ever could be. We have acquired these skills only through reading. Most of the time we are not even aware of what these skills are, and they are certainly not explained in the majority of teacher-training institutions. (p.6)

Smith and the Goodmans assert that reading is the process of extracting meaning from the printed page and that children learn to read by reading. Consequently, the teacher is responsible for providing appropriate cues and feedback, acting as a model, providing guidance, and generally facilitating students' "search for information that is relevant to their attempts [emphasis added] to comprehend and learn" (Smith, 1975, p. 7). As an ex- ample of holistic learning (although neither the Goodmans nor Smith use this particular term), Smith (1973) describes the following situation:

The skill of riding a bicycle comes with riding a bicycle. We do not offer a child lectures, diagrams, and drills on the component skills of bicycle riding - we sit him on the saddle and use a guiding hand or training wheels to make sure he does not fall off while he teaches himself [emphasis added] in the precarious art of keeping balance. Forcing him to worry about laws of motion and centers of gravity would obviously confuse him. (p. 195)

The learning process advocated by the Goodmans and Smith is rooted in the belief that all children want to learn and that teachers must allow them to assume greater responsibility for their own learning. This does not mean that teachers become passive observers. When learning is a shared responsibility, teachers assume the role of facilitators rather than directors.

Three additional points need to be addressed in this brief overview of the holistic approach to language arts. First, the Goodmans are often associated with "miscue analysis"; miscue analysis, in turn, is often associated with the analysis or studying of oral reading miscues (i.e., where what the child reads is different from what is on the printed page) for remedial purposes ( $Y$. Goodman \& Burke, $1973,1980)$. While these associations are true to some extent, the Goodmans' focus is broader than miscue analysis; and miscue analysis, in turn, involves more than oral reading. K. Goodman's (1969) studies of miscues were mainly aimed at enhancing the understanding of the reading process and perfecting a theoretical model of the reading process. Furthermore, miscue analysis involves comprehension in the form of retelling what was read in addition to oral reading. Oral reading is merely a possible means to the end. The study of miscues for remedial purposes is valuable only if it increases comprehension (e.g., Goodman, 1973).

Second, while the preceding statements have emphasized reading, it cannot be stated 
too strongly that the holistic approach is not limited to reading. The Goodmans (e.g., 1977) and Smith (e.g., 1977) have not studied reading to the exclusion of the other components of language which are often incorporated within their work. K. Goodman and Y. Goodman (1977) wrote: "We are convinced that oral and written language differ more in how they are taught than in how they are learned" (p. 323). The collective works of Smith and the Goodmans indicate that they have studied all aspects of language. Furthermore, they advocate that our approaches to teaching reading or other language components more closely approximate the manner in which most very young children learn oral language.

Third, readers are reminded that this brief overview cannot pretend to adequately describe the holistic approach to language arts or to provide insight into the reading/language process.

\section{PERSPECTIVES OF LD PROFESSIONALS}

The intent of this special issue of the LDQ was to compile a series of articles that would represent the views of a diverse group of LD professionals. Consequently, from the manuscripts recommended by the LDQ reviewers, articles were chosen guided by the results from a simple open-ended questionnaire completed by the LDQ consulting editors and by state/province chapter officers of the Division for Children with Learning Disabilities (DCLD).

The primary purpose of the questionnaire was to identify two or three issues in the areas of research, school programs, and teacher training that LD professionals viewed as important when considering language arts and learning disabilities. The following was contained in the questionnaire:

1. What do you see as the major issues related to $\mathrm{RESEARCH}$ in reading and language arts as this research relates to learning disabilities?

2. What do you see as the major issues related to reading and language arts SCHOOL PROGRAMS as they affect learning disabled students?
3. What do you see as the major issues related to TRAINING LD TEACHERS in the areas of reading and language arts?

4. A space for other comments was also provided.

A total of 58 individuals responded to this questionnaire. $^{3} \mathrm{~A}$ majority of the $23 \mathrm{LDQ}$ consulting editors and 35 DCLD state/province officers completing the questionnaire were teacher educators; the next largest group was made up of administrators (mainly at the local education agency level). Also represented in this group were LD teachers, school psychologists, supervisors, and counselors.

The input from these individuals was varied, but five general issues appeared throughout the sections on research, school programs, training, and "other comments". These issues related to (a) comprehension-centered or holistic reading, (b) the need for efficacy and validity in assessment and instructional techniques, (c) identifying LD populations in research, (d) interdisciplinary concerns, and (e) the need for more and better research. The following is a brief description of each of these issues in rank order according to the frequency with which they were mentioned by the respondents.

Comprehension-centered reading. Almost all respondents indicated a major interest in comprehension-centered reading within at least one of the four areas on the questionnaire. While terminology varied, the majority of the individuals seemed to favor the comprehension-centered (holistic) approach to reading/language arts versus the skills approach. Numerous statements related to the need for more information about research and programs focusing on the holistic approach. Little mention was made of the perceptual/mentalistic processes approach.

Need for efficacy and validation. Almost equal in importance to the issue of comprehension-centered language arts was the request for information related to the efficacy of reading and language arts approaches, instructional techniques and programs, and the need for validated language arts tests. Many individuals specified interest in deter- 
mining whether or not programs and tests were effective/valid with LD students in particular as opposed to being shown to be effective/valid with only "normal" students. Others questioned whether or not LD students could actually profit from the same programs and techniques as those used in "regular" education.

Identifying LD populations in research. While not exclusive to the area of language arts, many comments focused on identification of LD students. Related to this LDQ special issue, the respondents emphasized that research with LD samples must be tightly controlled and the LD sample specifically defined. Some individuals also suggested that "reading disabled" students and "learning disabled" students may be the same.

Interdisciplinary concerns. Many individuals referred to the need for interaction among disciplines or territorial rights/problems. The majority of these respondents seemed to focus on the positive aspects of such interaction (e.g., how can the various disciplines best work together, how can the LD people learn from the reading people, and vice versa). While none of the following articles specifically focuses on interaction among disciplines, many of their reference sections are evidence that such interaction is a reality.

Need for more and better research. A number of respondents indicated an interest in a variety of research issues including: (a) What are the academic characteristics of LD students? (b) What is the relationship among reading, language development, and other variables? (c) What variables are related to reading/language arts failure?

Because the five issues just outlined were so pervasive, they were used as the basis for choosing the following ten manuscripts for this special issue after the submitted manuscripts had been subjected to the standard LDQ reviewing process.

Chiang, Thorpe, and Darch ("Effects of Cross-Age Tutoring on Word-Recognition Performance of Learning Disabled Students") explore the efficacy of cross-age tutoring in LD classrooms. While the authors studied older LD students tutoring younger LD students on word recognition, cross-age tutoring could likely be used to increase performance in other language tasks.

Harber ("Issues in the Assessment of Language and Reading Disorders in Learning Disabled Children") provides a thought-provoking discussion of various issues in language assessment. Because many of the questionnaire respondents expressed an interest in the area of accurately identifying LD students, Harber's discussion of the discrepancy component as it relates to language may prove interesting to many readers.

Huhn ("Readiness as a Variable Influencing Comprehension in Secondary Content-Area Reading: A Cognitive View") describes readiness as the relationship between the learner and the learning task, a holistic frame of reference, which does not limit readiness to young children. The impact of readiness on secondary content-area reading and practical implications are considered.

Three articles present research related to language characteristics of LD students and practical implications based on their finds. Kavale ("The Reasoning Abilities of Normal and Learning Disabled Readers on Measures of Reading Comprehension") studied sixthgrade students. Poplin, Gray, Larsen, Banikowski, and Mehring ("A Comparison of Components of Written Expression Abilities in Learning Disabled and Non-Learning Disabled Students at Three Grade Levels") used subjects in the third through the eighth grade. Reid and Hresko ("A Developmental Study of the Relation Between Oral Language and Early Reading in Learning Disabled and Normally Achieving Children") report data on children, ages 5 to 7 . Their study utilizes two new tests (i.e., one measuring early language development and one measuring emerging reading ability) which may be of interest to some readers.

Leigh ("Whole-Language Approaches: Premises and Possibilities") provides a description of the whole-language (or holistic) approach. He discusses major principles and applications of such an approach with LD students.

Lloyd, Cullinan, Heins, and Epstein ("Direct Instruction: Effects on Oral and Written Language Comprehension") conducted a research study in which the experimental groups were exposed to applied behavior 
analysis (ABA) and direct instruction methods while the control groups were exposed to more traditional methods including some perceptual and psychological training. The results favor the $\mathrm{ABA}$ and direct instruction methods.

Lovitt and Fantasia ("Two Approaches to Reading Program Evaluation: A Standardized Test and Direct Assessment") compare two types of evaluation typically conducted by teachers. While the data indicate that neither method is superior, the authors discuss factors which they believe tip the scale in favor of direct assessment.

Poteet ("Informal Assessment of Written Expression") discusses practical methods and procedures for informal assessment of written expressive language. He includes descriptive examples as well as a useful checklist.

The following articles attempt to address current trends in the language arts as they relate to learning disabilities. Using information from a host of other disciplines as a starting point, investigations include topics on current assessment techniques, comprehension-centered reading, and needed research in the area of language arts.

\section{REFERENCES}

Blumenthal, A.L. The process of cognition. Englewood Cliffs, NJ: Prentice-Hall, 1977.

Brown, R.W. Psycholinguistics. New York: The Free Press, 1970.

Bruner, J.S. Beyond the information given. New York: W.W. Norton \& Co., 1973

Bryan, T.H., \& Bryan, J.H. Understanding learning disabilities (2nd ed.). Sherman Oaks, CA: Alfred Publishing, 1978.

Chomsky, N. Aspects of the theory of syntax. Cambridge, MA: MIT Press, 1965.

Goodman, K.S. Analysis of oral reading miscues: Applied psycholinguistics. Reading Research Quarterly, 1969, 5 (1), 4-30.

Goodman, K.S. Miscues: Windows on the reading process. In K.S. Goodman (Ed.), Miscue analysis: applications to reading instruction. Urbana, IL: National Council of Teachers of English, 1973.

Goodman, K.S. Effective teachers of reading know language and children. Elementary English, 1974, 51, 823-828.

Goodman, K.S., \& Goodman, Y.M. Learning about psycholinguistic process by analyzing oral reading. Harvard Educational Review, 1977, 47, 317.

Goodman, K.S., \& Smith, F. On the psycholinguistic method of teaching reading. Elementary School Journal, 1971, 71, 177-181.

Goodman, Y.M., \& Burke, C. The reading miscue inventory. New York: MacMillan, 1973.

Goodman, Y.M., \& Burke, C. Reading strategies: Focus on comprehension. New York: Holt, Rinehart and Winston, 1980.

Halliday, M.A.K. Learning how to mean. Explorations in the development of language. New York: Elsevier, 1975.

Hammill, D.D. The field of learning disabilities: A futuristic perspective. Learning Disability Quarterly, 1980, 3 (2), 2-9.

Hammill, D.D., \& McNutt, G. Correlates of reading: The consensus of thirty years of research. Austin, TX: Pro-Ed, in press.

Haring, N.G., \& Bateman, B. Teaching the learning disabled child. Englewood Cliffs, NJ: Prentice-Hall, 1977.

Huey, E.B. The psychology and pedagogy of reading. New York: MacMillan, 1908. (MIT Reprint, 1968).

Kaluger, G., \& Kolson, C.J. Reading and learning disabilities (2nd ed.). Columbus, $\mathrm{OH}$ : Charles E. Merrill, 1978.

Kirk, S.A., \& Elkins, J. Characteristics of children enrolled in the child service demonstration centers. Journal of Learning Disabilities, 1975, 8, 630-637.

Kirk, S.A., Kliebhan, J.M., \& Lerner, J.W. Teaching reading to slow and disabled learners. Boston: Houghton Mifflin, 1978.

Miller, G.A. Language and communication. New York: McGraw-Hill, 1951.

Piaget, J. The science of education and the psy. chology of the child. New York: Viking, 1971.

Mercer, C.D. Children and adolescents with learning disabilities. Columbus, $\mathrm{OH}$ : Charles $\mathrm{E}$. Merrill, 1979.

Smith, F. (Ed.). Psycholinguistics and reading. New York: Holt, Rinehart \& Winston, 1973.

Smith, F. Comprehension and learning: $A$ conceptual framework for teachers. New York: Holt, Rinehart \& Winston, 1975.

Smith, F. Making sense of reading - and of reading instruction. Harvard Educational Review, 1977, 47, 386-395.

Smith, F. Understanding reading: A psycholinguistic analysis of reading and learning to read (2nd ed.). New York: Holt, Rinehart \& Winston, 1978.

Smith, F. Reading without nonsense. New York: Teachers College Press, Columbia University, 1979. 
Vygotsky, L.D. Thought and language (E. Hanfman \& G. Vakar, Eds. and Trans.). Cambridge, MA: MIT Press, 1962. (Originally published, 1936) Wallace, G., \& McLoughlin, J.A. Learning disabilities: Concepts and characteristics (2nd ed.). Columbus, OH: Charles E. Merrill, 1979.

\section{FOOTNOTES}

'The references cited for these individuals are meant to be examples only. Their contributions are not limited to these works.
${ }^{2}$ While all Frank Smith's books have merit, Reading Without Nonsense (1979) is recommended for a first sampling.

'I would like to express my appreciation to all the professionals who took the time to answer this questionnaire. The responses received have been invaluable in preparing this special issue of the LDQ.

Requests for reprints should be addressed to: Gaye McNutt, College of Education, University of Oklahoma, Norman, OK 73019. 